\title{
Sturm der Bilder: registros videográficos de las actitudes iconoclastas
}

\author{
Sergio Martín \\ Universitat Politècnica de València, serma10s@bbaa.upv.es
}

\begin{abstract}
Sturm der Bilder's proposal is a journey through the destructive gesture of the human being towards images and, consequently, on their identity contexts. Traditionally, iconoclastic phenomena are reduced to certain crises of the image that do not encompass the complexities of this attitude towards the ideological. This is how hegemonic visual policies are dissolved in the face of the ruin of their representation, showing the violence of institutional narratives. For this, this video documents those records that are transferred from the cultural heritage to the human bodies themselves.
\end{abstract}

On the other hand, the video itself is directly related to the debate on patrimonial inheritance, dominated through iconoclastic strategies that influence symbolic murder. However, these same acts have managed to open up the analysis of conservation and cultural management on each occasion. This fact, in turn, indicates how new media, such as video and photography, can be technologies of the record for documentation and preservation in the absence of a reference, as happened with Jean Cocteau's photobook "Death and Statues" (1946). Therefore, the video would preserve the images as fragments, fleeting and hurtful as memories, in order to protect the memory from the copy and the reproducibility.

For all these reasons, the short film seeks phenomenological traces through the gestures reflected in the management of violence towards images in history. A journey of critical thought in the hands of a vehemence that fails to hide the possibility of truth behind the act of what is known as "the destruction of art."

Keywords: iconoclasm, art history, image, film-essay 


\section{Resumen}

La propuesta de Sturm der Bilder es un recorrido por el gesto destructivo del ser humano hacia las imágenes $y$, en consecuencia, sobre sus contextos identitarios. Tradicionalmente, los fenómenos iconoclastas son reducidos a ciertas crisis de la imagen que no abarcan las complejidades de esta actitud frente a lo ideológico. Es así como las políticas visuales hegemónicas se ven disueltas frente a la ruina de su representación, mostrando la violencia de los relatos institucionales. Para ello, este vídeo documenta esos registros que se trasladan desde el patrimonio cultural hasta los mismos cuerpos humanos.

Por otra parte, el propio vídeo se relaciona directamente con el debate de la herencia patrimonial, dominada a través de estrategias iconoclastas que inciden en el asesinato simbólico. No obstante, estos mismos actos han logrado abrir en cada ocasión el análisis de la conservación y la gestión cultural. Este hecho, a su vez, señala cómo los nuevos medios, como el vídeo y la fotografía, pueden ser tecnologías del registro para la documentación y preservación a falta del referente, como sucedió con el fotolibro de Jean Cocteau "La muerte y las estatuas" (1946). Por ende, el vídeo preservaría a las imágenes como fragmentos, fugaces e hirientes como recuerdos, a modo de resguardar la memoria desde la copia y la reproductibilidad.

Por todo ello, el cortometraje busca las huellas fenomenológicas a través de los gestos reflejados en la gestión de la violencia hacia las imágenes en la historia. Un viaje del pensamiento crítico en manos de una vehemencia que falla en ocultar la posibilidad de verdad tras el acto de lo conocido como "la destrucción del arte".

Palabras clave: iconoclasia, historia del arte, imagen, ensayo audiovisual 


\section{Introducción}

La destrucción es un acto que simbólicamente ha sido representado como elemento de lo reprobable, acciones que no buscan ninguna consecución beneficiosa para la historia cultural que la sufre. Estos eventos condenan al olvido eliminando toda huella rastreable, lo que consiste en un retorno al vacío, a un supuesto punto de partida. Destruir implica alejarse de lo que se ha tratado de considerar como civilizado, generando relatos que tratan de demonizarlo acusando a este de ser una carencia de educación (Schiller, 2018). Educación como cultura, cultura como dispositivo civilizatorio (Bauman, 2013). No obstante, a pesar de todo ello estos fenómenos han estado siempre presentes. La destrucción forma parte activa de los procesos de transformación en los cuales puede, incluso, concluir en la creación de algo nuevo. Sin ir muy lejos, las propias materias primas deben ser transformadas, destruyendo su forma, para poder obtener productos manufacturados. De este mismo modo, la destrucción ha sido una herramienta de desmontaje ideológico, señalando con estos fenómenos el disenso frente a estructuras hegemónicas de poder. Por un lado o por el otro, destruir forma parte vital de la existencia y ha dado varios casos que deben ser estudiados con detenimiento. Asumir que la destrucción es necesaria no implica no poder establecer un contacto crítico, preguntándose las razones de su formación y evaluando sus condiciones de existencia. La violencia que se genera debe ser medida para entender cómo y por qué destruir. Es por este motivo que en las últimas décadas ha surgido un campo de análisis que trata de dar respuestas a esos interrogantes, cuestionando ya no qué es sino cuándo podría ser. Uno de los campos más conocidos son los llamados estudios sobre iconoclasia (Gamboni, 2014).

El vídeo que aquí se propone se basa en este punto de partida, cómo se ejerce esa violencia a través de la iconoclasia. Pero, ¿por qué la iconoclasia? El estudio de lo que se denomina como la "destrucción del arte" ha sido una de las más fructíferas áreas de investigación en las que poner en cuestión las probabilidades de los actos destructivos, ya no por su mera formalidad sino por la complejidad política y social que representan. Por ello, a lo largo del presente escrito se realizará un breve recorrido sobre el interés actual de observar dichos sucesos y cómo sirven para dar algunas aproximaciones a la cuestión de comprender mejor cuándo se destruye. Para ello, el escrito se divide en dos secciones: en primer lugar, un acercamiento a la iconoclasia y su justificación como objeto de estudio; en segundo lugar, el inevitable debate sobre la conservación y el patrimonio que se sucede a raíz de estas situaciones, uniendo cómo iconoclasia y vídeo conforman varios niveles de conservación. Por último, en este escrito no habrá unas conclusiones definidas, ya que aquí solo se busca señalar los detalles importantes que ha favorecido la producción del cortometraje Sturm der Bilder y su proyección futura, por lo que esto implica comprender la necesidad y utilidad de la investigación artística. 
El cortometraje es un ensayo audiovisual que arranca desde la intencionalidad de averiguar que supone destruir, cuándo se considera que algo es destruido y si, realmente, se puede conseguir hacer desaparecer a lo violentado de la historia cultural.

\section{Estructuras iconoclastas}

La iconoclasia se institucionaliza como paradigma con la teología (Otero, 2012), dando base a los debates que desarrollaron las diferentes crisis de representación religiosa en el pasado. Más tarde, esta comienza a ser estudiada a partir del s. XVIII por las disciplinas académicas de la Historia y la Historia del Arte, analizando dichos fenómenos como actitudes contextuales y, por ende, anecdóticas. Sin embargo, desde los años setenta del siglo pasado algunos historiadores comenzaron a detectar que la actitud destructiva que caracterizada a esos eventos no se constreñía a empresas aisladas en el tiempo, sino que se podrían entender como una acción atemporal, siendo más cotidiano de lo que se había entendido hasta la fecha.

Estas miradas se llevan a cabo desde la interdisciplinariedad como se observa en enfoques psicológicos (Freedberg, 2017), antropológicos (Belting, 2012) o filosóficos (Mitchell, 2016). A lo largo de estas variadas aportaciones se construyó el cuerpo de un campo de análisis que, como se ha mencionado anteriormente, se conoce como estudios sobre iconoclasia. En estos mismos se trata de averiguar y analizar los distintos parámetros que intervienen en la ejecución de estos actos, lo que implica una observación detallada de las causas y consecuencias de la destrucción. Esta dirección redirige la cuestión hacia las posibles razones de disenso que les han dado pie.

Una de las consecuencias más notables del surgimiento de este campo es cómo se adscribe a otros paradigmas de estudio que convergen en el análisis de estos fenómenos. Por ejemplo, las aportaciones que buscan complejizar el campo teórico de las imágenes. Este mismo tiene una tradición arraigada en las renovaciones disciplinares de las metodologías historiográficas (Didi-Huberman, 2018), en las cuales se comienzan a emplear a las imágenes y el pensamiento visual de un modo más específico y transversal, tal y como se puede observar en el recorrido de las propuestas warburgianas hasta llegar al giro pictórico o icónico (García, 2011), las cuales han favorecido el desarrollo de otras perspectivas como son las múltiples áreas del conocimiento que tratan de observar los Estudios Visuales. En cuanto a la iconoclasia, el estudio de las imágenes y su relación con su contexto es vital, ya que es necesario poder acercarse a las razones de la necesidad de destruir una imagen, así como el problema del cómo hacerlo. Para esta línea podría servir el enfoque del antropólogo Hans Belting cuando desarrolla una teoría que ofrece una herramienta para acercarse a estos eventos. Belting propone y razona que la imagen se compone de varios estadios que viajan desde la inmaterialidad de la idea hasta su formación matérica a través de 
un medio o dispositivo específico para su visibilidad en el plano de lo real (2012). Esto implica, que destruir el referente no supone una victoria de anulación de las ideologías que conformaron la imagen conflictiva. Esta puede sobrevivir a través de su supervivencia, ya sea en otras imágenes o en su herencia oral. Esta teoría del potencial de las imágenes a través de sus arraigos en los imaginarios visuales se vincula con la propuesta fantasmagórica warburgiana y, más adelante, benjaminiana (Benjamin, 2021). Las imágenes, por ende, no desaparecen por completo, suelen dejar un rastro capaz de encarnarse en un futuro. Incluso, esta intención de desaparición puede generar aún más atención sobre el elemento afectado, como ha sucedido en algunos casos de damnatio memoriae en el pasado.

Por otro lado, otra de las cuestiones más relevantes de la iconoclasia es el modo en el que ha sido categorizada desde dentro, es decir, la inevitable confrontación de la oposición iconoclasta-idólatra. Este mecanismo funciona para que en todo momento haya un conflicto entre el iconoclasta que considera que el otro actúa como idólatra, lo que significa que este último vive en el supuesto engaño ideológico mediante su forma. Esto estructura una visión cíclica que acorta la inmensidad de matices que se generan en estos conflictos. La filósofa Marie-José Mondzain amplía esta percepción incluyendo el estudiar la figura del iconódulo, un ente necesario para la defensa de la veneración de imágenes sin caer en el supuesto engaño del idólatra (Mondzain, 2012). El iconódulo sería la persona que discierne los hilos que conforman una imagen, atendiéndose a estas de un modo crítico. Por lo tanto, este elemento pone sobre la mesa el factor de estudio del mundo visual sin caer en paradigmas apocalípticos del exceso de imágenes en el que flotan los debates actuales (Soto, 2020). De este modo, se pueden estudiar los conflictos iconoclastas desde la perspectiva de sus condiciones de posibilidad, lo que lleva a cabo un mayor detenimiento en las características específicas, ya no solo del acontecimiento en particular sino sobre el potencial de las imágenes: ¿cuáles son las huellas que han sobrevivido en el tiempo?, ¿por qué se ataca la forma?, ¿cómo se entienden estas estrategias de acción política?

Por ende, estas visiones teóricas buscan acercar el debate tanto a la acción destructiva cómo a sus elementos constitutivos, generando una hipótesis en la que la iconoclasia más que un golpe explosivo es una actitud intelectual frente a las imágenes. Pensarlo como una actitud es similar al concepto carnavalesco de Mijaíl Bajtin, en el que durante esta festividad el pueblo podría criticar la hegemonía sin pena de castigo ninguna (Rodriguez, 2003). La crítica es la vía por la que la iconoclasia actúa de manera activa, destruya o no, contra el pensamiento que se materializa en una imagen. Es así como Walter Benjamin también se interesó por la actitud de un niño pequeño frente a un juguete, en el que su propia curiosidad le llevaba a desmontarlo para conocerlo mejor. La destrucción que ejerce el niño es para poder analizar con detenimiento lo que tiene entre manos (Didi-Huberman, 2008). Ambas posturas son ejemplos de actitudes 
iconoclastas, que no son simplemente contra la representación divina, sino que se transforman en una actitud atemporal que atraviesa todo debate en favor de conocer mejor las condiciones de las imágenes. Es por este motivo que la "vandalización" y ataque contra esculturas del pasado año 2020 ha sido destacada por historiadores como Enzo Traverso, debatiendo que esas acciones son signos de que hay una memoria en esas imágenes dentro del imaginario colectivo, hay unas emociones que fomentan dichas representaciones y todo esto genera un debate, una discusión sobre el surgimiento de esos sentimientos arraigados en situaciones específicas. Indican la necesidad de un diálogo, de un desmontaje de los relatos que conforman las imágenes y su ataque no es nada más que la necesidad de señalar un suceso, un malestar. Destruir es la herramienta de crítica contra las estructuras que mandaron hacer ciertas imágenes, el mensaje que se transmite es la del disenso de un propósito vinculado a la construcción de estas. De este modo, es cómo la iconoclasia abre el debate de la conservación de patrimonio y cómo esta es discutida a través de las propias particularidades del vídeo como medio, así como sus propias estrategias de conservación.

\section{Conflictos de la preservación}

El propio fenómeno de tratar de eliminar la forma material como asesinato simbólico de la idea que representa no se puede desvincular del acto de destrucción, que en su vertiente más clásica pone en conflicto la preservación y obliga a entrar en el tablero de juego a las estrategias de conservación. Por lo tanto, la conservación del patrimonio siempre está en el debate iconoclasta en su doble vertiente: como restauración y como prevención. Hay ciertos ataques iconoclastas, sin entrar en sus especificaciones contextuales, que tratan de prevenirse mediante la seguridad de los objetos a conservar. Miles de ejemplos pueden ser desplegados sobre los espacios museísticos; no obstante, más paradigmáticos son los casos de traslado de obras como el traslado de las obras del Louvre en la Segunda Guerra Mundial o las del Museo del Prado en la Guerra Civil española. Incluso, durante el siglo XXI, los múltiples conflictos llevados a Oriente Medio, según Occidente, han proliferado los ataques a objetos antiguos. De este tipo de acontecimientos se desarrollan planes de protección que van desde el aumento de la seguridad en los espacios de exhibición, así como su completa sustitución mediante réplicas. Aun así, no todos estos ataques son por dañar al objeto en sí, sino que tienen intenciones intrínsecas que algunos autores han tratado de estudiar a raíz de casos como los sucedidos por el Dáesh o la destrucción de los budas de Bamiyán. La hipótesis es que tras la superficial justificación religiosa podrían caber motivos geopolíticos de control del patrimonio que Occidente considera relevantes. Un ataque a estas obras y su completa desaparición generan incertidumbre y miedo, atacan con pocos medios a otros estados que se vanaglorian su nivel civilizatorio o su 
poderío militar y cultural. Por ende, la destrucción de estos objetos pone sobre la mesa el concepto de plusvalía de las imágenes (Vives-Ferrandiz, 2015). Esta plusvalía está muy relacionada con las huellas sobra las que se estructuran esas imágenes en el tiempo, haciendo referencia a sus distintos contextos de creación. Estos eventos implican que el ataque de dicho objeto es un ataque a todo lo que lo rodea, dejando un mensaje al que se considere como oponente a mermar. El caso de Bamiyán, a pesar de sus razones religiosas, algunos autores han analizado este evento como un ataque a la idea de patrimonio de Occidente, ya no solo a los monumentos como objetos auráticos de la historia cultural, sino también contra el turismo que generan estos mismos. Así pues, no solo se destruye, sino que se ataca la propia idea tardocapitalista del turismo y su vinculación a las civilizaciones occidentales que ven en la cultura un caso de elitismo cultural que a su vez sirve como fuente de ingresos, explotando estas necesidades creadas a través de la gestión cultural. Algo similar sucedió con los ataques llevados del Dáesh con la ciudad de Palmira. La primera vez que fue tomada la ciudad no fueron destruidos ninguno de sus monumentos, pero tras su liberación por parte del ejército americano y su recaptura posterior por el mismo Dáesh comenzaron con las demoliciones, a modo de contraataque simbólico buscando frenar el avance estadounidense. A raíz de estos sucesos, Estados Unidos y Reino Unido han desembocado en un delirio de conservación de un patrimonio considerado mundial. Se han sucedido varios planes de reconstrucción digital 3D en los que se pretende imitar las estructuras eliminadas por el grupo terrorista para no perder dichos monumentos gracias al registro fotográfico y su manipulación digital. En 2016, Londres instaló una réplica 3D del Arco del Triunfo de Palmira como señal de solidaridad al legado arqueológico; mientras que por otro lado hubo un plan millonario de reconstruir el Templo de Bal, el cual introdujo el debate sobre la necesidad prioritaria de llevar a cabo dicha reconstrucción pudiendo emplear esa inversión en reconstruir las estructuras socio-económicas de Siria, planificando llevar a cabo la reconstrucción patrimonial más adelante.

Estos conflictos ponen de manifiesto preguntas que cuestionan qué se considera Patrimonio Histórico, cuál sería su importancia y, por ende, cómo debería protegerse. Cabría también plantear cuándo debe poder realizarse y en qué medios se pueden ejercer. Estas estrategias de reconstrucción digital han abierto un mundo que ya se intuía en la democratización de los medios tecnológicos alrededor de los años sesenta. El registro tecnológico, ya sea fotográfico o videográfico, ha puesto de manifiesto su increíble capacidad de tomar y preservar la imagen de lo que capta, estableciéndose como una potente herramienta de conservación, al menos en imagen. A día de hoy, estas imágenes están sirviendo para interpretar y reconstruir elementos perdidos en el pasado. Pero en ambos casos siempre hay un factor de interpretación, un factor de idealización que se traduce en la necesidad de materializarlo. No obstante, esto excede el presente artículo que, tal y cómo se presenta a lo largo del vídeo, su única pretensión 
es plantear dicho paradigma para no olvidar la necesidad de seguir preguntando. Las esculturas perdidas en París en el 1946 hoy son recordadas a través del fotolibro de Jean Cocteau "La muerte y las estatuas", por lo que el vídeo también recoge algunas imágenes dañadas, imitando esa metodología, estableciendo ya no su conservación sino alertando de su preservación. Algo complejo ya que estos medios no son infalibles, las constantes actualizaciones que se van desarrollando y el progreso tecnológico hacen que la historia de los nuevos medios sea acelerada $y$, por ende, devoradora. Actualmente, en pleno debate sobre las nomeclaturas de si seguir empleando palabras como cinematográfico, metraje o vídeo en el paradigma de lo digital y lo virtual, supone uno de los mayores retos a enfrentar desde el campo de las Humanidades, ya que son desde estas desde donde se frenan estos procesos y se analizan, se conflictúan y se les encuentra la mejor gestión posible para su época. Por ello, la representación de la iconoclasia a lo largo de Sturm der Bilder propone varias capas de significación en dos vías: las imágenes y su conservación, de cómo podría funcionar la iconoclasia hasta la problemática del patrimonio, incluso a través de los nuevos medios y sus futuros problemas de restauración implícitos de la tecnología.

\section{4. (In)Conclusiones}

Así pues, llegando al final de esta propuesta de diálogo en futuro, Sturm der Bilder se crea a raíz de las inquietudes de la renovación historiográfica que buscan abrir los horizontes de la teoría de las imágenes mediante casos de estudio y su influencia sociopolítica. La iconoclasia, por ende, no es un mero asunto de vandalización, sino que siempre están implícitas tensiones simbólicas que buscan ser repensadas en estos actos de destrucción, cuándo se llevan a cabo, a qué tratan de referirse y cómo son ejecutados. Esto pone sobre la mesa el inmenso poder que aún retiene la representación y su inevitable vinculación con los procesos de maduración cultural del ser humano. Debemos aprender a entender las reacciones frente a las imágenes sin encajonarlo todo en cuestiones mínimas de significación. Estas deben traspasar las fronteras y entrar en el debate cultural y político, teniendo que actualizarse las prácticas artísticas para estar alerta de los mensajes directos que envía la iconoclasia hacia su perspectiva sobre los objetos artísticos, una labor que desde la historiografía artística ya se está realizando. Esto supone ya no solo una actualización del debate sobre las imágenes y su función cultural, sino también la de su posible conservación, tal y como se observa al remover los cimientos de los patrones civilizatorios que aún retienen estrategias de colonización. $Y$ todo ello, a través de otro medio que está gritando por su reconsideración a través de lo digital: el vídeo. De este modo, se pueden presuponer las necesidades que están exigiendo los debates en torno a la iconoclasia y su necesidad para poder comprender mejor el futuro que está por venir. Es así como desde la iconodulía se ha tratado de acercarse al ponzoñoso mundo de la 
Sergio Martín

iconoclasia para extraer la incógnita de que no era lo que nos contaron. Por lo tanto, ¿qué debemos hacer?, ¿cómo hemos comprendido el mundo que nos rodea? ¿por qué no hemos ampliando las lecturas posibles de conflictos tan próximos? ¿cuándo nos sentaremos a escuchar?

\section{Referencias}

BELTING, H. (2012), Antropología de la imagen (3ㄹed.). Madrid, España: Katz Editores.

BENJAMIN, W. (2021). Tesis sobre el concepto de historia y otros ensayos sobre historia y política. Madrid, España: Alianza Editorial.

DIDI-HUBERMAN, G. (2008). Ante el tiempo. Buenos Aires, Argentina: Adriana Hidalgo editora S.A.

DIDI-HUBERMAN, G. (2018). La imagen superviviente: historia del arte y tiempo de los fantasmas según Aby Warburg (na3 ed.). Madrid, España: Abada, D.L.

FREEDBERG, D. (2017). Iconoclasia. Historia y psicología de la violencia contra las imágenes. Vitoria-Gasteiz, España: Sans Soleil Ediciones.

GAMBONI, D. (2014). La destrucción del arte. Iconoclasia y vandalismo desde la Revolución Francesa. Madrid, España: Ediciones Cátedra.

GARCÍA, A. (2011), Filosofía de la imagen. Salamanca, España: España. Ediciones Universidad de Salamanca

MITCHELL, W. J. T. (2016). Iconología. Imagen, texto, ideología. Buenos Aires, Argentina: Capital Intelectual.

MONDZAIN, M.J. (2012). “Delenda est" el ídolo. En: AAVV. (eds.) Iconoclastia. La ambivalencia de la mirada (pp. 123-147). Madrid, España: La Oficina de Arte y Ediciones, S.L.

OTERO, C. (2012). Introducción. La imagen como paradoja. En: AAVV. (eds.) Iconoclastia. La ambivalencia de la mirada (pp.9-36). Madrid, España: La Oficina de Arte y Ediciones, S.L.

RODRÍGUEZ, G. (2003). La marginalidad como opción en Katherine Mansfield. postmodernismo, feminismo y relato corto. (Tesis doctoral). Universidad de Granada, Granada, España.

SCHILLER, F. (2018). Cartas sobra la educación estética de la humanidad. Barcelona, España: Quaderns Crema, S.A.

SOTO, A. (2020). La performatividad de las imágenes. Santiago de Chile, Chile: Ediciones metales pesados.

VIVES-FERRÁNDIZ, L. (2015). (No) son sólo imágenes: iconoclasia y yihad 2.0. En: repositorio.uam.es. [Consultado el 10-5-2021] Disponible en: <https://repositorio. uam.es/handle/10486/677347> 